\title{
FACTORES DE TRANSCRIPCIÓN INVOLUCRADOS EN RESPUESTAS MOLECULARES DE LAS PLANTAS AL ESTRÉS OSMÓTICO
}

\section{TRANSCRIPTION FACTORS INVOLVED IN MOLECULAR RESPONSES OF PLANTS TO OSMOTIC STRESS}

\author{
Soledad García-Morales ${ }^{1}$, Fernando C. Gómez-Merino ${ }^{2 \star}$, Libia I. Trejo-Téllez ${ }^{1}$ \\ y Édgar B. Herrera-Cabrera ${ }^{3}$
}

\begin{abstract}
${ }^{1}$ Campus Montecillo, Colegio de Postgraduados. km 36.5 Carr. México-Texcoco. 56230, Montecillo, Texcoco, Edo. de México. Tel y Fax 01 (595) $9510198 .{ }^{2}$ Campus Córdoba, Colegio de Postgraduados. km 348 Carr. Federal Córdoba-Veracruz. 94946, Congregación Manuel León, Amatlán de los Reyes, Veracruz. ${ }^{3}$ Campus Puebla, Colegio de Postgraduados. km 125.5 Carr. Federal México-Puebla. 72760, Santiago Momoxpan, San Pedro Cholula, Puebla.
\end{abstract}

*Autor para correspondencia (fernandg@colpos.mx)

\section{RESUMEN}

El estrés osmótico ocasionado por frío, salinidad y sequía representa uno de los mayores factores limitantes, que afecta negativamente el desarrollo y la productividad de las plantas en todo el mundo. La aclimatación de las plantas al estrés osmótico depende de la regulación de cascadas de redes bioquímicas y moleculares involucradas en la percepción del agobio, la transducción de señales y la expresión de genes específicos relacionados con tal limitante ambiental. Los componentes clave que controlan y modulan la aclimatación al estrés son los factores de transcripción, los cuales son pequeñas proteínas que regulan la expresión de muchos otros genes que conducen a la modulación de complejos mecanismos de aclimatación, por lo que constituyen un grupo de moléculas de interés crucial para entender los mecanismos que emplean las plantas para tolerar este tipo de agobio ambiental. En las plantas superiores cuyos genomas han sido secuenciados completamente, las familias de factores de transcripción son numerosas, y oscilan entre 79 y 81, según la especie. El objetivo de esta revisión es analizar el papel de los factores de transcripción en los mecanismos moleculares de respuesta al estrés osmótico, con énfasis en la familia NAC (NAM, ATAF1-2 y C UC), y su relación con las respuestas de las plantas a este tipo de estrés.

Palabras clave: Sequía, salinidad, frío, estrés abiótico, red de transducción de señales, NAC.

\section{SUMMARY}

Osmotic stress caused by cold, salinity and drought are among the major stresses, which adversely affect plant growth and productivity worldwide. Plant acclimation to osmotic stress depends on regulation of biochemical and molecular networks involved in stress perception, signal transduction and expression of specific genes related to such environmental restrictions. The key components controlling and modulating stress acclimation pathways are transcription factors, small proteins encoded by single genes that regulate expression of many other genes, leading to the modulation of complex acclimation mechanisms, Transcription factors represent a major target for understanding the mechanisms used by plants to develop tolerance against these kinds of environmental constraints. In higher plants with complete genome sequences, the number of transcription factor families is large and varies between 79 y 81 , depending on the species. The objective of this review is to analyze the role of transcription factors in the molecular response mechanisms to osmotic stress, with emphasis on the NAC

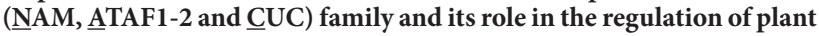
responses to osmotic stress.

Index words: Drought, salinity, cold, abiotic stress, signal transduction network, NAC.

\section{INTRODUCCIÓN}

El estrés osmótico ocasionado por sequía, salinidad y frío frecuentemente limita el crecimiento y la productividad de las plantas. Éstas responden y se aclimatan a condiciones adversas con una serie de cambios morfológicos, fisiológicos, bioquímicos y moleculares, regulados por múltiples rutas de señalización en respuesta al estrés. En Arabidopsis y arroz (Oryza sativa L.) existe una superposición entre los patrones de expresión de los genes inducidos por sequía, salinidad y frío, y se han identificado más de 300 genes inducidos por estos tipos de estrés, y más de la mitad de los genes inducidos por sequía también son inducidos por salinidad, lo que indica la existencia de una intersección aparente entre las respuestas a la sequía y a la salinidad. Por el contrario, solamente $10 \%$ de los genes inducidos por sequía también son inducidos por frío (Nakashima y Yamaguchi-Shinozaki, 2010).

En condiciones de estrés, la regulación de la expresión génica está determinada por la tasa de transcripción, misma que depende de varios factores de transcripción y de sus interacciones con secuencias regulatorias en el promotor de los genes blanco (Agarwal y Jha, 2010).

Los factores de transcripción son proteínas capaces de unirse específicamente a secuencias cortas de ADN (elementos en cis) localizadas en los promotores de genes, y de interactuar con el complejo de pre-iniciación de la transcripción para inducir o inhibir la actividad de la enzima ARN polimerasa II. De esta manera, los factores de transcripción modulan la tasa de transcripción de sus genes blanco a través de un sistema denominado regulón (Nakashima et al., 2009).

Las plantas han desarrollado mecanismos muy elaborados para percibir señales externas y expresar respuestas adaptativas a nivel morfológico, fisiológico, bioquímico y molecular. La tolerancia al estrés abiótico está mediada 
por diversas reacciones bioquímicas y procesos fisiológicos controlados por mecanismos moleculares de naturaleza multigénica. La percepción del estrés y la consiguiente transmisión de señales para activar una respuesta adaptativa, son componentes críticos para la supervivencia de las especies en condiciones ambientales extremas, y en el caso de sequía, salinidad o frío, la regulación transcripcional que yace en la base de los procesos moleculares juega un papel preponderante.

En este trabajo se revisan las funciones de los factores de transcripción en los mecanismos moleculares de respuesta al estrés osmótico ocasionado por sequía, salinidad y frío, con mayor énfasis en la familia NAC, la cual tiene funciones en la tolerancia de las plantas a diversos tipos de estrés abiótico.

\section{EL ESTRÉS OSMÓTICO}

La sequía, la salinidad y el frío son factores que conducen a la deshidratación celular, la cual causa estrés osmótico que a su vez limita la absorción de agua del suelo por las plantas. El estrés osmótico también ocasiona la producción de especies reactivas de oxígeno (ROS, reactive oxygen species) que afectan negativamente la estructura celular y el metabolismo. Las respuestas tempranas a la sequía y a la salinidad son idénticas excepto por el componente iónico, e incluyen la disminución de la fotosíntesis o cambios en los procesos hormonales (Verslues et al., 2006).

Cuando el estrés osmótico es moderado, hojas y tallos disminuyen su crecimiento con la consiguiente acumulación de solutos y la manifestación del ajuste osmótico, mientras que la raíz puede continuar creciendo (Hadiarto y Tran, 2011).

La aclimatación al estrés osmótico es un proceso complejo, que involucra numerosos cambios que incluyen disminución del crecimiento, cambios en la expresión de genes, incremento en los niveles de ácido abscísico (ABA), acumulación de solutos compatibles y de proteínas protectoras, ajuste en el transporte iónico e incrementos en los niveles de antioxidantes (Saibo et al., 2009; Hadiarto y Tran, 2011).

\section{PERCEPCIÓN Y TRANSDUCCIÓN DE SEÑALES DE ESTRÉS}

La percepción de las señales es el primer paso en la respuesta de las plantas al estrés osmótico. Un sensor del estrés puede detectar cambios ambientales y transmitir, específicamente, la señal inicial del estrés a los blancos celulares (Gao et al., 2008). Cada estímulo ambiental proporciona a las células vegetales información específica, que es percibida a través de diferentes tipos de sensores (Gao et al., 2008;
Hirayama y Shinozaki, 2010).

El estrés ocasionado por sequía, salinidad o frío induce la acumulación momentánea de $\mathrm{Ca}^{2+}$ en el citoplasma, proveniente del espacio apoplástico o de la liberación de depósitos internos como los orgánulos celulares. Los canales responsables de la entrada de $\mathrm{Ca}^{2+}$ representan un tipo de sensor para la señalización del estrés. La liberación interna de $\mathrm{Ca}^{2+}$ es controlada por ligandos de canales sensibles a $\mathrm{Ca}^{2+}$, los cuales funcionan como segundos mensajeros (Rodríguez et al., 2005).

Otros tipos de sensores son los receptores tipo cinasa de proteínas, que consisten de un dominio extracelular que puede funcionar en la unión de ligandos o interacciones proteína-proteína, un dominio transmembranal y un dominio cinasa intracelular (Rodríguez et al., 2005; Gao et al., 2008; Yamasaki et al., 2008).

En contraste con la percepción, en la transducción de señales se han identificado varios componentes, aunque se desconoce cómo interactúan las moléculas entre sí y dónde están posicionadas en la compleja red de señalización. Inmediatamente después de la percepción del estímulo, se generan moléculas de señalización como segundos mensajeros, por ejemplo: $\mathrm{Ca}^{2+}$, inositoltrifosfato y ROS. Subsecuentemente, los segundos mensajeros activan, corriente abajo, una cascada de señales que fosforilan los factores de transcripción, y éstos regulan la expresión de un grupo de genes involucrados en la aclimatación al estrés (Hirayama y Shinozaki, 2010). La fosforilación por cinasa de proteínas es el mecanismo de regulación más común e importante en la transducción de las señales (Gao et al., 2008).

La red de transducción de las señales para frío, sequía y salinidad, se puede dividir en tres tipos principales de señalización: I) Señalización del estrés osmótico/oxidativo, que usa los módulos de las cinasas de proteínas activadas por mitógeno o MAPK (mitogen-activated protein kinase), las cuales involucran la generación de enzimas que remueven especies reactivas de oxígeno y componentes antioxidantes, así como osmolitos; II) Señalización dependiente de $\mathrm{Ca}^{2+}$, que conduce a la activación de genes de proteínas abundantes en la embriogénesis tardía (LEA, late embryogenesis abundant proteins), involucradas en respuesta al estrés, las cuales en su mayoría no tienen funciones definidas; y III) Señalización de proteína demasiado sensible a sal (SOS, salt overlay sensitive), que depende de $\mathrm{Ca}^{2+}$ y regula la homeostasis iónica, la cual involucra a la ruta SOS y es específica del estrés iónico (Rodríguez et al., 2005; Gao et al., 2008; Hadiarto y Tran, 2011).

Las rutas de transducción de señales pueden compartir elementos y componentes de diversos factores de estrés, 
y los genes de respuesta temprana codifican a factores de transcripción que activan a los genes de respuesta tardía (Hirayama y Shinozaki, 2010). A pesar de la existencia de componentes y ramas específicas, las rutas de señalización para salinidad, sequía o frío pueden interactuar con el ácido abscísico (ABA) y converger en múltiples pasos (Peleg y Blumwald, 2011).

ABA es una hormona vegetal involucrada en diversos procesos fisiológicos, como la regulación de la apertura estomática y de las respuestas al estrés (Gao et al., 2008; Verslues et al., 2006). La aplicación exógena de ABA induce la expresión de una serie de genes que también responden a salinidad, a sequía y a frío. Yamaguchi-Shinozaki y Shinozaki (2006) propusieron dos cascadas de señalización: una inducida por $\mathrm{ABA}$ y otra independiente de este fitorregulador. En estas cascadas existen dos elementos principales que actúan en cis: ABRE (ABA-Responsive Element, secuencia TACCGACAT) y DRE (Dehydration-Responsive Element, secuencia ACGTGG/TC), los cuales funcionan en la expresión de genes dependientes e independientes de ABA, respectivamente, y explican los sistemas reguladores de la transcripción involucrados en la expresión de genes en respuesta al estrés (Nakashima y Yamaguchi-Shinozaki, 2010).

\section{LOS FACTORES DE LA TRANSCRIPCIÓN}

Estos factores son proteínas que se unen a elementos específicos presentes en el promotor de un gen blanco. La estructura proteica de un factor de transcripción típico consiste de dos dominios: el dominio de unión al ADN, responsable de unirse a elementos específicos que actúan en cis en las regiones del promotor, y el dominio regulatorio responsable de la regulación transcripcional de los genes blanco, el cual se une a la maquinaria de transcripción (Shen et al., 2009). De esta manera, los factores de transcripción inducen (activadores) o inhiben (represores) la actividad de la ARN polimerasa II, y así regulan la expresión genética (Saibo et al., 2009). En las plantas hay diferentes familias de factores de transcripción, clasificadas con fundamento en su dominio de unión al ADN (Gómez-Merino et al., 2009). El resumen de estos hallazgos se presenta en el Cuadro 1, en donde se puede notar el creciente número de especies cultivadas estudiadas, y que toman como modelos principales a Arabidopsis thaliana y arroz.

Varios factores de transcripción pueden interactuar con los elementos que actúan en cis en las regiones promotoras, y forman un complejo de iniciación transcripcional sobre la caja TATA (promotor central) corriente arriba del sitio de iniciación de la transcripción. El complejo de iniciación

Cuadro 1. Familias de factores de transcripción y proteínas clasificadas por especie vegetal.

\begin{tabular}{lcccc}
\hline Especie & $\begin{array}{c}\text { Número total de } \\
\text { proteínas }\end{array}$ & $\begin{array}{c}\text { Número de factores } \\
\text { de transcripción }\end{array}$ & $\begin{array}{c}\text { Número de familias de } \\
\text { factores de transcripción }\end{array}$ & $\begin{array}{c}\text { Miembros de la } \\
\text { familia NAC }\end{array}$ \\
\hline Oryza sativa subsp. indica & 43027 & 1943 & 56 & 163 \\
Oryza sativa subsp. japonica & 58760 & 2438 & 56 & 186 \\
Sorghum bicolor & 35810 & 1828 & 54 & 125 \\
Zea mays & 62184 & 3376 & 56 & 190 \\
Carica papaya & 27829 & 1394 & 58 & 82 \\
Arabidopsis lyrata & 32234 & 1736 & 58 & 121 \\
Arabidopsis thaliana & 32125 & 2023 & 58 & 135 \\
Populus trichocarpa & 45183 & 2599 & 58 & 182 \\
Vitis vinifera & 47097 & 2450 & 58 & 142 \\
Cucumis sativus & 27725 & 1783 & 57 & 102 \\
Glycine max & 48707 & 3557 & 57 & 183 \\
Manihot esculenta & 46478 & 2210 & 58 & 124 \\
Medicago truncatula & 52086 & 1613 & 56 & 73 \\
Mimulus guttatus & 27989 & 1686 & 57 & 102 \\
Prunus persica & 28299 & 1521 & 58 & 113 \\
Ricinus communis & 31953 & 1298 & 57 & 97 \\
\hline
\end{tabular}

Datos obtenidos de la plataforma Plant Transcription Factor Database, disponible en: http://plntfdb.bio.uni-potsdam.de/v3.0/ (Pérez-Rodríguez et al., 2010) y http://planttfdb.cbi.edu.cn/index.php (Zhang et al., 2011). 
transcripcional activa la ARN polimerasa para iniciar la transcripción de los genes de respuesta al estímulo o estrés (Yamaguchi-Shinozaki y Shinozaki, 2006).

Las respuestas al estrés osmótico requieren de la síntesis de proteínas metabólicas importantes, como las que involucran la síntesis de osmoprotectores, y la operación de proteínas reguladoras en la ruta de transducción de señales, como las cinasas de proteínas o los factores de transcripción. Dado que la mayoría de estas respuestas implican el control y la regulación de la expresión de genes, los factores de transcripción juegan un papel importante en la respuesta de las plantas al estrés y en el desarrollo (Saibo et al., 2009; Agarwal y Jha, 2010).

En las rutas de transducción de las señales, varios factores de transcripción y elementos que actúan en cis funcionan no solamente como inductores o interruptores moleculares para la expresión génica, sino también como puntos terminales de la transducción de señales en los procesos de señalización (Tran et al., 2007). La fosforilación de proteínas reguladoras es también un acontecimiento importante en el control de la expresión génica en organismos superiores, por lo que múltiples interacciones proteína-proteína y ADN-proteína con frecuencia determinan la tasa de la transcripción en determinadas condiciones ambientales.

Un solo factor de transcripción puede controlar la expresión de muchos genes blanco. Así, un grupo de genes controlados por un cierto tipo de factor de transcripción es conocido como un regulón. En la respuesta de las plantas al estrés osmótico se pueden identificar al menos cuatro regulones: 1) El regulón DREB/CBF; 2) El regulón NAC y ZF$\mathrm{HD}$; 3) El regulón AREB/ABF; y 4) El regulón MYC/MYB (Saibo et al., 2009). Estos regulones están ligados a rutas involucradas en las respuestas al estrés osmótico y pueden ser dependientes o independientes de ABA (YamaguchiShinozaki y Shinozaki, 2006). Por otro lado, los elementos que actúan en cis en los promotores de los genes son: el elemento de respuesta a la deshidratación de repetición C (CRT/DRE), la secuencia de reconocimiento NAC (NACR), el elemento sensible al ABA (ABRE) y los elementos MYCR/ MYBR (Shinozaki y Yamaguchi-Shinozaki, 2007).

El regulón $\mathrm{DREB} / \mathrm{CBF}$ está involucrado principalmente en las respuestas al frío y es conservado en el reino vegetal (Saibo et al., 2009). Yamaguchi-Shinozaki y Shinozaki (1994) identificaron un elemento que actúa en cis que, además del elemento de respuesta a ABA (ABRE), también está presente en el promotor del gen RD29A (responsive to dehydratation 29A), un gen inducido por sequía, salinidad y frío. Este elemento fue llamado elemento de respuesta a la deshidratación (dehydration-resposive element/C-repeat, DRE/ CRT) y fue caracterizado como dependiente de ABA. El motivo central de este elemento que actúa en cis es CCGAC y los factores de transcripción que se unen a este elemento fueron llamados factores de unión a CRT o proteínas 1 de unión a DRE (DREB1/CBF) (Nakashima et al., 2009).

Los factores de transcripción DREB1/CBF activan la expresión de muchos otros genes que codifican a proteínas involucradas en la producción de osmoprotectores y antioxidantes (Saibo et al., 2009). Los genes blanco DREB2 (RD29A, RD29B, RD17, y LEA14) son inducidos solamente por la deshidratación, lo cual indica que las proteínas DREB2 son activadas a través de modificaciones post-traduccionales con la finalidad de regular la expresión de los genes corriente abajo (Sakuma et al., 2006).

El descubrimiento del regulón NAC y ZF-HD derivó del estudio de una ruta independiente de ABA que involucró al gen $E A R L Y$ responsive to dehydration stress 1 (ERD1) en respuesta a salinidad y a sequía, sin acumulación de ABA (Nakashima y Yamaguchi-Shinozaki, 2010). Esta ruta reveló la presencia de factores de transcripción de la familia NAC y de la familia del homeodominio de dedos de zinc (homeodomain zinc finger, HD-ZF), identificados como esenciales para activar al gen ERD1. Sin embargo, la sobre expresión de genes NAC en Arabidopsis incrementa la tolerancia a sequía sin activar al gen $E R D 1$, lo que sugiere la necesidad de otros factores para controlar su expresión en condiciones de estrés (Tran et al., 2007).

Por su parte, el gen stress-responsive NAC1 (SNAC1) fue aislado de una variedad de arroz de secano. Las plantas que sobre expresan el gen SNAC1 mostraron un fenotipo indeseado y enanismo, comparado con las que expresan el gen $D R E B 1 / C B F$ a través de insertos diseñados por ingeniería genética (Ito et al., 2006), lo que revela un mecanismo de acción diferente. El incremento en la tolerancia a sequía puede ser debido, en parte, a la reducción en la tasa de transpiración (incremento en el cierre estomático) y a un aumento en la sensibilidad al ABA (Saibo et al., 2009).

El regulón $\mathrm{AREB} / \mathrm{ABF}$ fue identificado en los promotores de los genes inducidos por ABA (Nakashima et al., 2009). Para la transcripción no es suficiente una sola copia del ABRE, por lo que conjuntamente con elementos de acoplamiento como el CE1 (coupling element 1) y CE3, constituye un complejo en respuesta a $\mathrm{ABA}$ para regular los genes HVA1 y HVA22 en trigo (Triticum aestivum L.) (Shen et al., 1996). Las proteínas ABF o AREB (ABA-responsive element binding protein/ABRE-binding factor) son factores de transcripción tipo bZIP (basic leucine zipper) que se unen al motivo ABRE y activan la expresión de los genes dependientes de ABA (Peleg y Blumwald, 2011).

Algunos factores de transcripción, como AREB1 y 
AREB2, requieren de una modificación post-traduccional para ser activados al máximo. Estas modificaciones incluyen probablemente, una fosforilación dependiente de ABA (Saibo et al., 2009). La mayoría de los elementos de acoplamiento conocidos son similares al ABRE. De hecho, la secuencia de DRE/CTR puede servir como un elemento de acoplamiento del ABRE en repuesta a $\mathrm{ABA}$, lo que sugiere la existencia de una interacción entre los regulones DREB y AREB (Nakashima et al., 2009).

El grupo de genes $A R E B / A B F$, en su mayoría son redundantes y de expresión específica, unos en tejidos vegetativos en tanto que otros lo hacen en tejidos reproductores (Peleg y Blumwald, 2011). Los genes AREB1/ABF2, AREB2/ABF4 y $A B F 3$ se expresan principalmente en tejido vegetativos, mientras que $A B I 5$ y $E E L$ se expresan en la semilla durante la maduración o durante la germinación (Nakashima et al., 2009). La expresión del gen OsABI5 en las plántulas es estimulada por ABA y salinidad, pero reprimida por sequía y frío; su sobre expresión incrementa la tolerancia del arroz a la salinidad (Nakashima et al., 2009).

En cuanto al regulón MYC/MYB, la expresión del gen $R D 22$ (responsive to dehydration 22) inducido por sequía, también es estimulada por ABA (Nakashima y YamaguchiShinozaki, 2010). La región del promotor del gen $R D 22$ contiene a los elementos cis de MYC (CANNTG) y de MYB (C/ TAACNA/G). Los factores de transcripción sólo se acumulan después del incremento en los niveles de ABA (Saibo et al., 2009). Para activar al gen RD22, los factores AtMYC y AtMYB actúan cooperativamente. La sobre expresión de estos factores de transcripción a través de promotores inducibles incrementa la sensibilidad a ABA y la tolerancia a sequía (Nakashima y Yamaguchi-Shinozaki, 2010). En soya (Glycine $\max$ L.) se identificaron 156 genes de la familia $M Y B$, de los cuales 43 fueron inducidos por ABA, sequía, salinidad y frío (Liao et al., 2008).

Es importante destacar que cientos de factores de transcripción están implicados en la respuesta a diversos estímulos y a factores de estrés como salinidad, sequía y frío (Hirayama y Shinozaki, 2010). A menudo, los miembros de una misma familia responden de diferente manera al estrés. Pero algunos genes de respuesta al estrés pueden compartir los mismos factores de transcripción, lo que se refleja en una superposición del perfil de expresión de genes inducidos por diferentes tipos de estrés. En este sentido, se han identificado genes de diferentes familias y especies, que son inducidos tanto por sequía, salinidad, frío y ABA.

Una de las familias más numerosas de factores de transcripción que regulan las respuestas de las plantas al estrés, recientemente identificada, es la familia NAC. Este nombre deriva de las primeras tres proteínas descritas que contie- nen el dominio de unión al ADN, llamados NAM (no apical meristem), ATAF1-2 (Arabidopsis thaliana activation factor) y CUC (cup-shaped cotyledon) (Christianson et al., 2010), que están implicadas en procesos como el desarrollo vegetativo y el reproductivo, y en las respuestas al estrés biótico y abiótico (Olsen et al., 2005), la movilización de nutrientes, la regulación de la senescencia (Ogo et al., 2008), la división celular y el crecimiento (Christianson et al., 2010).

Las proteínas NAC contienen un dominio de unión al ADN altamente conservado en su extremo $\mathrm{N}$-terminal, y un dominio variable en su extremo C-terminal. En la región $\mathrm{N}$ terminal existen, al menos, cinco sitios diferentes de unión al ADN (Shen et al., 2009); estos sitios incluyen la secuencia de reconocimiento de los NAC en respuesta a sequía (NAC recognition sequence, NACRS) que contiene el motivo central CACG; el motivo IDE2 en respuesta a la deficiencia de hierro, que contiene la secuencia $\mathrm{CA}(\mathrm{A} / \mathrm{C}) \mathrm{G}(\mathrm{T} / \mathrm{C})(\mathrm{T} / \mathrm{C} / \mathrm{A})$ (T/C/A); el sitio de unión CBNACBS de la proteína CBNAC unida a calmodulina, que tiene el motivo central GCTT; el elemento de unión NAC de la pared secundaria (SNBE), que contiene una secuencia consenso de 19 pares de bases (T/A)NN(C/T) (T/C/G)TNNNNNNNA(A/C)GN(A/C/T) (A/T) (Jensen et al., 2010; Le et al., 2011), y tiene la capacidad de mediar las interacciones proteína-proteína.

Por otro lado, la alta variabilidad de la región C-terminal hace que las proteínas NAC puedan actuar como activadores o represores de la transcripción en diferentes circunstancias (Le et al., 2011). Los dominios C-terminal de numerosos factores de transcripción de la familia NAC también muestran actividad de unión a proteínas; mientras que las regiones C-terminal de otros NAC contienen motivos transmembranales (TM, transmembrane motif) responsables del anclaje a la membrana plasmática (Shen et al., 2009). El dominio NAC no sólo interactúa con otras proteínas, sino también con el dominio NAC de otros miembros de la familia NAC para formar dímeros (Olsen et al., 2005).

Análisis bioinformáticos recientes han permitido predecir un número variable de factores de transcripción de la familia NAC, los cuales se anotan en el Cuadro 1 donde también se enlistan las especies con genoma secuenciado (Pérez-Rodríguez et al., 2010; Zhang et al., 2011). En especies cuyos genomas aún no han sido secuenciados completamente, se han reportado los siguientes números: 48 genes NAC en cebada (Hordeum vulgare); 92 en el pasto Panicum virgatum; 46 en caña de azúcar (Saccharum spp.); 42 en trigo; 26 en naranja (Citrus sinensis); 21 en girasol (Helianthus annuus); 41 en tomate (Solanum lycopersicum); 40 en papa (Solanum tuberosum) y 42 en tabaco (Nicotiana tabacum) (Christiansen et al., 2011; Le et al., 2011; Shen et al., 2009; Zhang et al., 2011). Recientemente se ha dado una 
importancia creciente a la caracterización de estos genes, y se ha estudiado su función en plantas cultivadas y plantas modelo.

En Arabidopsis thaliana, tres genes NAC (ANAC019, ANAC055, y ANAC072) son inducidos por sequía, salinidad y bajas temperaturas. Plantas transgénicas de Arabidopsis que sobre expresan estos genes incrementaron la tolerancia a sequía, comparado con el tipo silvestre (Tran et al., 2004; Tran et al., 2007).

Nogueira et al. (2005) reportaron que el gene SsNAC23 en caña de azúcar es homólogo del gen OsNAC5 de arroz, y que está asociado con respuestas a frío, a daños por herbívoros y a déficit hídrico. Posteriormente se encontró que este gen se expresa fuertemente en inflorescencias de caña de azúcar, particularmente en meristemos florales, así como en células de la vaina del haz vascular de hojas maduras (Ditt et al., 2011).

De un análisis de microarreglos en arroz se identificó el gen SNAC1, cuya sobre expresión eleva la tolerancia a sequía al modular el cierre de estomas (Hu et al., 2006). Este es uno de los pocos genes caracterizados a nivel de campo durante el estado reproductivo de la planta y en condiciones severas de sequía, donde las plantas transgénicas de arroz no presentaron cambios fenotípicos ni reducciones significativas en el rendimiento.

El gen OsNAC6 fue seleccionado del análisis del perfil de expresión de genes de arroz bajo varios factores de estrés, y dicho gen mostró ser inducido por frío, salinidad, sequía, ABA, jasmonato (JA), lesiones físicas y enfermedades. Sin embargo, las plantas transgénicas de arroz que expresaron constitutivamente este gen también mostraron retraso en el crecimiento y bajos rendimientos, aunque mostraron un incremento en la tolerancia a la deshidratación y a la alta salinidad (Nakashima et al., 2007).

Otro gen $N A C$ de arroz, OsNAC6/SNAC2, es inducido por el estrés abiótico y por JA, y su sobre expresión incrementa la tolerancia a frío, a sequía y a salinidad; las plantas transgénicas superaron al tipo silvestre en estabilidad de la membrana celular durante el estrés por frío, y en tasa de crecimiento y germinación bajo condiciones de salinidad (Hu et al., 2008).

Tran et al. (2009) estudiaron 31 genes NAC en soya, de los cuales nueve (GmNAC002, 003, 004, 010, 012, 013, 015, 020 y 028) mostraron ser inducidos por deshidratación en tallos y raíces, por lo que se consideran como candidatos potenciales para programas de mejoramiento genético.

El gen ONAC063 de arroz es inducido por alta salinidad en raíces, así como por tratamientos con ROS y alta presión osmótica. La expresión ectópica de ONAC063 en Arabidopsis thaliana origina mayor tolerancia a salinidad y a presión osmótica (Yokotani et al., 2009).

La sobre expresión del gen OsNAC10 en arroz bajo el control del promotor constitutivo GOS2 y del promotor específico de raíz $R C c 3$, incrementó la tolerancia a sequía, salinidad y frío en etapa vegetativa. En etapa reproductiva, la sobre expresión de este gen bajo el promotor $R C c 3$ aumentó el rendimiento en grano de 25 a $42 \%$ en condiciones de sequía, y de 5 a 14 \% bajo riego convencional (Jeong et al., 2010).

Al analizar el perfil de expresión del gen TaNAC69 mediante microarreglos y qRT-PCR (transcripción inversa cuantitativa acoplada a la reacción en cadena de la polimerasa), Xue et al. (2011) encontraron que su expresión está asociada positivamente con las respuestas del trigo tanto al estrés biótico como al abiótico. En líneas transgénicas de trigo que sobre expresan el gen TaNAC69 bajo el control del promotor inducible $\mathrm{HvDhn} 4 \mathrm{~s}$, se encontró que produjeron más biomasa y fueron más tolerantes a la deshidratación. Los mismos autores reportaron que el promotor utilizado no afectó al peso ni al rendimiento de grano en el testigo sin sequía, por lo que tanto el gen TaNAC69 como el promotor $H v D h n 4 s$ pueden ser utilizados para mejorar el rendimiento de grano en ambientes propensos a sequía.

Similarmente, Mao et al. (2012) encontraron que la expresión del gen TaNAC2 de tabaco responde a sequía, salinidad, frío y ABA, y que su expresión ectópica en plantas de Arabidopsis thaliana les confirió mayor tolerancia a deshidratación, salinidad y bajas temperaturas.

Por su parte, Lu et al. (2012) reportaron que el gen $\mathrm{Zm}$ SNAC1 de maíz (Zea mays L.) es fuertemente inducido por frío, alta salinidad, sequía y $\mathrm{ABA}$, pero reprimido por ácido salicílico. En comparación con el tipo silvestre, su expresión ectópica en Arabidopsis condujo a hipersensibilidad a ABA y estrés osmótico en la etapa de germinación de semillas, pero mejoró la tolerancia a la deshidratación.

En Brassica napus, los genes BnNAC2 y BnNAC5 se expresaron en flores y tallos, y fueron inducidos por condiciones de alta salinidad, sequía y ABA. Su expresión ectópica aumentó considerablemente el crecimiento celular de Schizosaccharomyces pombe sensible a alta salinidad y estrés osmótico (Zhong et al., 2012).

Ramegowda et al. (2012) aislaron el gen EcNAC1 del cereal Eleusine coracana, el cual mostró fuerte inducción por deficiencia de agua y por salinidad, y en las plantas trangénicas de tabaco que lo expresan hubo bajos niveles de ROS y 
tolerancia al estrés, ambos ocasionados por polietilenglicol (PEG), manitol y salinidad.

Como una herramienta útil, Nakashima et al. (2012) propusieron que los genes que aportan tolerancia al estrés pero también causan efectos indeseables, podrían combinarse con promotores inducibles por estrés (como los promotores de arroz LIP9), como una estrategia para mejorar la tolerancia al estrés sin imponer efectos no deseados en el crecimiento.

En el Cuadro 2 se resumen los estudios efectuados hasta la fecha sobre las proteínas NAC y sus implicaciones en las respuestas a varios tipos de estrés. Aquí es necesario hacer notar que la mayor parte de los experimentos realizados sobre tolerancia al estrés osmótico se han enfocado a las etapas vegetativas del desarrollo, debido a que resulta más fácil y rápida la toma de datos, a pesar de que el estrés causa su mayor daño en las etapas reproductivas (CastañedaSaucedo et al., 2009).

Si bien muchos genes están implicados en la tolerancia al estrés, sólo algunos han demostrado ser útiles en condiciones de campo, debido a la complejidad en las interacciones y de la variabilidad de respuestas al ambiente. Sin embargo, el uso de técnicas biotecnológicas como el silenciamiento de genes mediante mutagénesis, microARN (mARN) o ARN de interferencia (ARNi), así como la expresión ectópica de genes para generar plantas transgénicas con mayor tolerancia al estrés, permitirán disminuir las pérdidas de rendimiento en las plantas de interés agronómico, una vez que estos hallazgos tecnológicos se hayan transferido a campo.

Hasta ahora, la mayor parte de los factores de transcripción NAC caracterizados han demostrado estar involucrados en respuestas al estrés. En particular, la tolerancia a estrés osmótico (causado por sequía, salinidad o frío) ha sido el centro de atención de muchos estudios. En estos procesos, la acumulación de ABA desencadena respuestas bioquímicas y moleculares de las plantas sometidas a estrés, lo que se refleja en el hecho de que la mayoría de los factores de transcripción NAC que confieren resistencia a sequía, principalmente, son inducidos por tratamientos con ABA (Christiansen et al., 2011).

Componentes de la regulación transcripcional recientemente estudiados son los microARN. Por ejemplo, Zhou et al. (2013) reportaron que el microARN319 (miR319) es uno de los primeros que han sido identificados y caracterizados en plantas, el cual actúa sobre el factor de transcripción TCP (TEOSINTE BRANCHED/CYCLOIDEA/PROLIFERATING CELL FACTORS [PCF]) como molécula blanco en arroz. La expresión ectópica de miR319 de arroz (Osa-miR319a) en el pasto Agrostis stolonifera originó ma- yor tolerancia a sequía y a salinidad, relacionada con mayor producción de ceras en las hojas, mayor retención de agua y reducida absorción de sodio. Los respectivos perfiles de expresión analizados demostraron que la expresión del gen AsNAC60 se reduce en plantas transgénicas que expresan el miR319. Este descubrimiento marca una nueva etapa en el estudio de los factores de transcripción NAC, y agrega nuevas estrategias para regular la tasa transcripcional de genes en plantas.

\section{CONCLUSIONES Y PERSPECTIVAS}

Las plantas responden de manera muy variada a factores de estrés osmótico como sequía, salinidad y frío. Estas respuestas son reguladas por mecanismos moleculares donde los factores de transcripción juegan un papel preponderante. En esta revisión se describe de manera general la importancia del estrés osmótico en las plantas, la percepción y la transducción de las señales, y la relevancia de los factores de transcripción en la regulación de las respuestas a este tipo de estrés. El análisis funcional de los factores de transcripción permite generar mayor información sobre las redes regulatorias involucradas en respuestas al estrés abiótico y la confluencia entre diferentes rutas de señalización durante la aclimatación al estrés.

Por esta razón se puede considerar a los factores de transcripción como componentes cruciales para el entendimiento de las bases moleculares que modulan las respuestas bioquímicas y fisiológicas de las plantas al estrés osmótico. De ellos, los factores de transcripción NAC, que son exclusivos de las plantas, se pueden considerar como elementos con gran potencial para el estudio de los mecanismos de resistencia/tolerancia al estrés osmótico en las plantas cultivadas.

México, por ser el segundo país más vulnerable a los efectos del cambio climático, y cuya producción agrícola puede caer en más de $25 \%$ por este cambio (Moyer y Storrs, 2010) si no se aplican medidas adecuadas para enfrentarlo, requiere con urgencia planear de manera estratégica el uso de estos avances científicos para generar innovaciones que permitan mejorar la actividad agrícola y con ello lograr la seguridad alimentaria nacional.

Si bien los primeros reportes sobre la conexión de estas proteínas con el estrés osmótico surgieron hace casi una década y poco se había avanzado en términos de plantas cultivadas, los reportes más recientes ya hacen alusión a sus funciones como reguladores clave de las respuestas al estrés osmótico en especies como arroz, maíz, soya, tabaco y caña de azúcar, todas ellas de importancia en la agricultura nacional. 
Cuadro 2. Estudios de proteínas NAC en respuesta a los factores de estrés ambiental.

\begin{tabular}{|c|c|c|c|c|}
\hline $\begin{array}{l}\text { Especie } \\
\text { experimental }\end{array}$ & Gen & Expresión/Represión & Funciones atribuidas & Referencia \\
\hline B. napus & $B n N A C 14$ & Sobre expresión & $\begin{array}{l}\text { Interactúa con otros activadores transcripcionales y confiere } \\
\text { tolerancia a frío, a deshidratación, a heridas e infecciones. }\end{array}$ & $\begin{array}{l}\text { Hegedus et al., } \\
2003\end{array}$ \\
\hline A. thaliana & $\begin{array}{l}\text { ANAC019, } \\
\text { ANAC055, } \\
\text { ANAC072 }\end{array}$ & Sobre expresión & Incrementa la tolerancia a sequía. & Tran et al., 2004 \\
\hline A. thaliana & AtNAC2 & Sobre expresión & $\begin{array}{l}\text { Incrementa el desarrollo de las raíces laterales. } \\
\text { Tolerancia a salinidad y a ABA. }\end{array}$ & He et al., 2005 \\
\hline O. sativa & ONAC300 & Sobre expresión & $\begin{array}{l}\text { Expresado en estados tempranos del desarrollo, } \\
\text { en vástago, raíz y flores. }\end{array}$ & Kusano et al., 2005 \\
\hline O. sativa & SNAC1 & Sobre expresión & Tolerancia a sequía y a salinidad. & Hu et al., 2006 \\
\hline A. thaliana & ANAC012 & Sobre expresión & $\begin{array}{l}\text { Regulador negativo del engrosamiento } \\
\text { de la pared del xilema. }\end{array}$ & Ko et al., 2007 \\
\hline O. sativa & $\begin{array}{l}\text { OsNAC6/ } \\
\text { SNAC2 }\end{array}$ & Sobre expresión & $\begin{array}{c}\text { Activador transcripcional en respuesta a estreses bióticos y } \\
\text { abióticos. Tolerancia a deshidratación, salinidad } \\
\text { y a enfermedades. }\end{array}$ & $\begin{array}{c}\text { Nakashima et al., } \\
2007\end{array}$ \\
\hline O. sativa & SNAC2 & Sobre expresión & $\begin{array}{l}\text { Incrementa la tolerancia a frío, a polietilenglicol, } \\
\text { a ABA y a salinidad. }\end{array}$ & Hu et al., 2008 \\
\hline O. sativa & IDEF2 & Represión (ARNi) & Interacciones asociadas con la homeostasis del Fe. & Ogo et al., 2008 \\
\hline A. thaliana & ONAC063 & Sobre expresión & Mayor tolerancia a salinidad y presión osmótica. & $\begin{array}{l}\text { Yokotani et al., } \\
2009\end{array}$ \\
\hline O. sativa & ONAC045 & Sobre expresión & Incrementa la tolerancia a sequía y a salinidad. & Zheng et al., 2009 \\
\hline O. sativa & OsNAC10 & Sobre expresión & $\begin{array}{l}\text { Tolerancia a sequía, a salinidad y a bajas temperaturas en el } \\
\text { estado vegetativo. Incrementa el rendimiento del grano. }\end{array}$ & Jeong et al., 2010 \\
\hline A. thaliana & ANAC036 & Sobre expresión & Involucrado en el crecimiento celular en las hojas. & Kato et al., 2010 \\
\hline A. thaliana & ORS1 & $\begin{array}{l}\text { Represión } \\
\text { (T-ADN) }\end{array}$ & $\begin{array}{l}\text { Regulación de la senescencia foliar. } \\
\text { Tolerancia a salinidad y a } \mathrm{H}_{2} \mathrm{O}_{2}\end{array}$ & $\begin{array}{l}\text { Balazadeh et al., } \\
\qquad 2011\end{array}$ \\
\hline A. thaliana & NTM2 & $\begin{array}{c}\text { Inserción de } \\
\text { transposón }\end{array}$ & Mayor tolerancia a salinidad durante la germinación. & Park et al., 2011 \\
\hline O. sativa & OsNAC5 & Represión (ARNi) & $\begin{array}{l}\text { Menor tolerancia al estrés por frío, } \\
\text { por sequía y por salinidad. }\end{array}$ & Song et al., 2011 \\
\hline O. sativa & OsNAC5 & Sobre expresión & $\begin{array}{l}\text { Incrementa la tolerancia a frío, a sequía y a } \\
\text { salinidad en arroz y en Arabidopsis. }\end{array}$ & Song et al., 2011 \\
\hline T. aestivum & TaNAC69 & Sobre expresión & Incremento en la tolerancia a la deshidratación. & Xue et al., 2011 \\
\hline A. thaliana & VNI2 & Sobre expresión & $\begin{array}{l}\text { Integra la respuesta al estrés ambiental y modula } \\
\text { la longevidad foliar. Tolerancia a salinidad y a ABA. }\end{array}$ & Yang et al., 2011 \\
\hline A. thaliana & $Z m S N A C 1$ & Sobre expresión & $\begin{array}{l}\text { Hipersensibilidad a ABA y estrés osmótico, } \\
\text { pero incrementó la tolerancia a la deshidratación. }\end{array}$ & Lu et al., 2012 \\
\hline A. thaliana & TaNAC2 & Sobre expresión & $\begin{array}{l}\text { Tolerancia a la deshidratación, } \\
\text { alta salinidad y bajas temperaturas. }\end{array}$ & Mao et al., 2012 \\
\hline N. tabacum & EcNAC1 & Sobre expresión & $\begin{array}{l}\text { Tolerancia al estrés por polietilenglicol, manitol } \\
\text { y salinidad, además de bajos niveles de especies } \\
\text { reactivas de } \mathrm{O}_{2} \text { en tabaco. }\end{array}$ & $\begin{array}{c}\text { Ramegowda et al. } \\
2012\end{array}$ \\
\hline S. pombe & $\begin{array}{l}B n N A C 2, \\
B n N A C 5\end{array}$ & Sobre expresión & $\begin{array}{l}\text { Incrementa el crecimiento en células sensibles } \\
\text { a alta salinidad y estrés osmótico. }\end{array}$ & Zhong et al., 2012 \\
\hline T. aestivum & SNAC1 & Sobre expresión & Confiere tolerancia a sequía y salinidad en trigo transgénico. & Saad et al., 2013 \\
\hline A. stolonifera & AsNAC60 & Represión (miR319) & $\begin{array}{c}\text { Mayor síntesis de ceras en hoja, mayor retención } \\
\text { de humedad y menor absorción de sodio. }\end{array}$ & Zhou et al., 2013 \\
\hline
\end{tabular}


Es entonces determinante el continuar el estudio de tales proteínas para fines de mejoramiento genético, mediante el uso de las tecnologías más avanzadas para su implementación. Ello implica combinar las técnicas de genética inversa, genómica, transcriptómica, proteómica y metabólomica en diferentes etapas del desarrollo y de condiciones de estrés, a fin de disponer de información crítica que permita elucidar las diferencias funcionales de los factores NAC y su relación con el control transcripcional. Puesto que numerosos genes tienen funciones cruciales en el crecimiento y desarrollo de las plantas, se requerirá analizar tanto las funciones de estos factores de manera individual como en red, para dilucidar los traslapes que haya entre las respuestas al estrés y el crecimiento vegetal, especialmente en la etapa reproductiva que es la que mayormente afecta la productividad de las plantas en condiciones de estrés.

Los avances en el conocimiento de los factores de transcripción, y en específico de los factores NAC, deben ser contrastados a la luz de las limitantes que ha mostrado el mejoramiento asistido por marcadores moleculares y la ingeniería genética. Por ejemplo, según Campos et al. (2004), la mayoría de los loci de caracteres cuantitativos (QTL) de tolerancia a sequía identificados tienen una utilidad limitada para ser aplicados en programas de mejoramiento genético, debido a que dependen de antecedentes genéticos o a que son sensibles al ambiente, además de que se desconocen las bases biofísicas de estas dependencias. Aún más, las condiciones climáticas imperantes durante el proceso de selección de la progenie dentro de las pruebas de múltiples ambientes que se llevan a cabo en los programas de mejoramiento convencional, pueden afectar de manera significativa las frecuencias alélicas en las poblaciones mejoradas y la tolerancia al estrés en las líneas comerciales liberadas.

En el ámbito de la ingeniería genética enfocada a la generación de organismos genéticamente modificados o transgénicos, es frecuente que los genes ortólogos de tolerancia a factores de estrés encontrados en una especie no produzcan el mismo resultado en otra especie transgénica, o que causen una reducción en el rendimiento en ausencia del estrés, como se especificó anteriormente. Esto puede ser debido a que los genes candidatos provienen de diferentes sistemas biológicos (monocotiledóneas $v s$. dicotiledóneas) o a que la expresión génica se indujo por eventos repentinos de sequía, o debido a que el efecto no fue medido en ausencia de estrés en el sistema modelo.

Muchos genes transferibles potencialmente asociados con tolerancia a sequía no afectan directamente esta característica de interés, y más bien dependen de cadenas de respuestas metabólicas complejas. No obstante, la falta de un comportamiento consistente de estos genes también puede ser debida al intenso proceso de mejoramiento de las especies cultivadas a lo largo de su historia. Como consecuencia, un fenotipo transgénico tolerante a sequía que se genera de manera relativamente fácil en una especie no mejorada como Arabidopsis thaliana, o incluso en cultivares antiguos de maíz, es más difícil de lograr en los híbridos élite actuales.

Los experimentos de tolerancia al estrés osmótico en campo son difíciles de conducir, aun si se dispone de condiciones controladas como el riego, debido a la variabilidad de las condiciones de clima, suelo, lluvia, plagas y enfermedades. Además, algunos genes transferibles pueden funcionar en rutas que interaccionan con el ambiente, lo que conduce a resultados inestables. El camino más apropiado para enfrentar estos desafíos es probar los genotipos en distintos sitios y a través de varios años, lo cual resulta muy caro y consume mucho tiempo. La alternativa en este sentido es el análisis de gran cantidad de caracteres fenotípicos en invernadero (Deikman et al., 2012), con métodos no destructivos para cuantificar biomasa, arquitectura de vástago, fotosíntesis, pigmentación, contenido de agua, y tasa transpiratoria, entre otros caracteres.

En la actualidad, la humanidad enfrenta dos retos que determinan el desarrollo sustentable. Por un lado incrementar la producción de alimentos para la creciente población mundial, que se proyecta alcanzará los 9 mil millones de personas hacia 2050, y por otro el cambio climático global que ocasiona situaciones más inestables de lluvia y mayor frecuencia de sequías y heladas, entre otros fenómenos que afectan negativamente la producción agrícola. Al respecto, el avance en el conocimiento de los mecanismos moleculares de respuesta a estrés osmótico está abriendo nuevas posibilidades para diseñar estrategias tendientes a generar respuestas adaptativas de las plantas a los nuevos entornos.

En esta revisión se han analizado los progresos surgidos hasta la fecha en torno a los factores de transcripción como moléculas claves que regulan la expresión de múltiples genes y rutas relacionadas con el estrés osmótico, con especial énfasis en los factores NAC como elementos determinantes de las respuestas adaptativas de las plantas al estrés por sequía, salinidad y frío, así como las limitantes que enfrenta la biotecnología para generar nuevos genotipos tolerantes a estas condiciones de estrés. El entendimiento de estas oportunidades y restricciones técnicas y operativas permitirá a agrónomos, fisiólogos, genetistas y biotecnólogos, diseñar mejores alternativas para obtener el mejor provecho de estos avances.

\section{BIBLIOGRAFÍA}

Agarwal P K, B Jha (2010) Transcription factors in plants and ABA dependent and independent abiotic stress signalling. Biol. Plant. 54:201-212. 
Balazadeh S, M Kwasniewski, C Caldana, M Mehrnia, M I Zanor, G P Xue, B Mueller-Roeber (2011) ORS1, an H2O2-responsive NAC transcription factor, controls senescence in Arabidopsis thaliana. Mol. Plant 4:346-360.

Campos H, M Cooper, J E Habben, G O Edmeades, J R Schussler (2004) Improving drought tolerance in maize: a view from industry. Field Crop. Res. 90:19-34.

Castañeda-Saucedo M C, L Córdova-Téllez, V A González-Hernández, A Delgado-Alvarado, A Santacruz-Varela, G García-de los Santos (2009) Physiological performance, yield, and quality of dry bean seeds under drought stress . Interciencia 34:748-754.

Christiansen M W, P B Holm, P L Gregersen (2011) Characterization of barley (Hordeum vulgare L.) NAC transcription factors suggests conserved functions compared to both monocots and dicots. BMC Res. Notes 4:302.

Christianson J A, E S Dennis, D J Llewellyn,I W Wilson (2010) ATAF NAC transcription factors: regulators of plant stress signaling. Plant Signal. Behav. 5:428-432.

Deikman J, M Petracek, J E Heard (2012) Drought tolerance through biotechnology: improving translation from the laboratory to farmers' fields. Curr. Opin. Biotechnol. 23:243-250.

Ditt R F, A Gentile, R G Tavares, S R Camargo, J H Fernandez, M J da Silva, M Menossi (2011) Analysis of the stress-inducible transcription factor $S s N A C 23$ in sugarcane plants. Sci. Agric. 68:454-461.

Gao J P, D Y Chao, H X Lin (2008) Toward understanding molecular mechanisms of abiotic stress responses in rice. Rice 1:36-51.

Gómez-Merino F C, L I Trejo-Téllez, A Tiessen (2009) Factores de transcripción: In: Fundamentos y Metodologías Innovadoras para el Mejoramiento Genético de Maíz. A Tiessen (ed). Fundación Ciencia Activa, Bogotá, Colombia. pp:127-163.

Hadiarto T, L-S P Tran (2011) Progress studies of drought-responsive genes in rice. Plant Cell Rep. 30:297-310.

He X J, R L Mu, W H Cao, Z G Zhang, J S Zhang, S Y Chen (2005) AtNAC2, a transcription factor downstream of ethylene and auxin signaling pathways, is involved in salt stress response and lateral root development. Plant J. 44:903-916.

Hegedus D, M Yu, D Baldwin, M Gruber, A Sharpe, I Parkin, S Whitwill, D Lydiate (2003) Molecular characterization of Brassica napus NAC domain transcriptional activators induced in response to biotic and abiotic stress. Plant Mol. Biol. 53:383-397.

Hirayama T, K Shinozaki (2010) Research on plant abiotic stress responses in the post-genome era: past, present and future. Plant J. 61:1041-1052.

Hu H H, M Q Dai, J L Yao, B Z Xiao, X H Li, Q F Zhang, L Z Xiong (2006) Overexpressing a NAM, ATAF, and CUC (NAC) transcription factor enhances drought resistance and salt tolerance in rice. Proc. Nat. Acad. Sci. USA 35:12987-12992.

Hu H H, J You, Y J Fang, X Zhu, Z Y Qi, L Z Xiong (2008) Characterization of transcription factor gene SNAC2 conferring cold and salt tolerance in rice. Plant Mol. Biol. 67:169-181.

Ito Y, K Katsura, M Maruyama, T Taji, M Kobayashi, M Seki, K. Shinozaki, K Yamaguchi-Shinozaki (2006) Functional analysis of rice DREB1/CBF-type transcription factors involved in coldresponsive gene expression in transgenic rice. Plant Cell Physiol. 47:141-153.

Jensen M K, T Kjaersgaard, M M Nielsen, P Galberg, K Petersen, C O'Shea, K Skriver (2010) The Arabidopsis thaliana NAC transcription factor family: structure-function relationships and determinants of ANAC019 stress signaling. Biochem. J. 426:183-96.

Jeong J S, Y S Kim, K H Baek, H Jung, S H Ha, Y D Choi, M Kim, C Reuzeau, J K Kim (2010) Root-Specific expression of OsNAC10 improves drought tolerance and grain yield in rice under field drought donditions. Plant Physiol. 153:185-197.

Kato H, T Motomura, Y Komeda, T saito, A Kato (2010) Overexpression of the NAC transcription factor family gene ANAC036 results in a dwarf phenotype in Arabidopsis thaliana. J. Plant Physiol. 167:571-577.

Ko J H, S H Yang, A H Park, O Lerouxel O, K H Han (2007) ANAC012, a member of the plant-specific NAC transcription factor family, negatively regulates xylary fiber development in Arabidopsis thaliana. Plant J. 50:1035-1048.
Kusano H, T Asano, H Shimada, K Kadowaki (2005) Molecular characterization of ONAC300, a novel NAC gene specifically expressed at early stages in various developing tissues of rice. Mol Genet. Genomics 272:616-626.

Le D T, R Nishiyama, Y Watanabe, K Mochida, K Yamaguchi-Shinozaki, K Shinozaki, L S P Tran (2011) Genome-wide survey and expression analysis of the plant-specific NAC transcription factor family in soybean during development and dehydration stress. DNA Res. 18:263-276.

Liao Y, H Zou, H W Wang, W K Zhang, B Ma, J S Zhang (2008) Soybean GmMYB76, GmMYB92, and GmMYB177 genes confer stress tolerance in transgenic Arabidopsis plants. Cell Res. 18:10471060 .

Lu M, S Ying, D F Zhang, Y S Shi, Y C Song, T Y Wang, Y Li (2012) A maize stress-responsive NAC transcription factor, ZmSNAC1, confers enhanced tolerance to dehydration in transgenic Arabidopsis. Plant Cell Rep. 31:1701-1711.

Mao X, H Zhang, X Qian, A Li, G Zhao, RJing (2012) TaNAC2, a NACtype wheat transcription factor conferring enhanced multiple abiotic stress tolerances in Arabidopsis. J. Exp. Bot. 63:29332946.

Moyer M, C Storrs (2010) How much is left? A graphical accounting of the limits to what one planet can provide. Scient. Am. 303:74-81.

Nakashima K, Takasaki H, J Mizoi, K Shinozaki, K Yamaguchi-Shinozaki (2012) NAC transcription factors in plant abiotic stress responses. Biochim. Biophys. Acta 1819:97-103.

Nakashima K, K Yamaguchi-Shinozaki (2010) Promoters and transcription factors in abiotic stress-responsive gene expression. In: Abiotic Stress Adaptation in Plants: Physiological, Molecular and Genomic Foundation. A Pareek, S K Sopory, H J Bohnert, Govindjee (eds). Springer. Dordrecht, The Netherlands pp:199-216.

Nakashima K, Y Ito, K Yamaguchi-Shinozaki (2009) Transcriptional regulatory networks in response to abiotic stresses in Arabidopsis and grasses. Plant Physiol. 149:88-95.

Nakashima K, L S P Tran, D V Nguyen, M Fujita, K Maruyama, D Todaka, Y Ito, N Hayashi, K Shinozaki, K Yamaguchi-Shinozaki (2007) Functional analysis of a NAC-type transcription factor OsNAC6 involved in abiotic and biotic stress-responsive gene expression in rice. Plant J. 51:617-630.

Nogueira F T S, P S Schlögl, S R Camargo, J H Fernandez, V E De Rosa Jr, P Pompermayer, P Arruda (2005) SsNAC23, a member of the NAC domain protein family, is associated with cold, herbivory and water stress in sugarcane. Plant Sci. 169: 93-106.

Ogo Y, T Kobayashi, R N Itai, H Nakanishi, Y Kakei, M Takahashi, S Toki, S Mori, N K Nishizawa (2008) A novel NAC transcription factor, IDEF2, that recognizes the iron deficiency-responsive element 2 regulates the genes involved in iron homeostasis in plants. J. Biol. Chem. 283:13407-13417.

Olsen A N, H A Ernst, L LLeggio, K Skriver (2005) NAC transcription factors: structurally distinct, functionally diverse. Trends Plant Sci. 10:79-87.

Park J, Y S Kim, S G Kim, J H Jung, J C Woo, C M Park (2011) Integration of auxin and salt signals by the NAC transcription factor NTM2 during seed germination in Arabidopsis. Plant Physiol. 156:537-549.

Peleg Z, E Blumwald (2011) Hormone balance and abiotic stress tolerance in crop plants. Curr. Opin. Plant Biol. 14:1-6.

Pérez-Rodríguez P, D M Riano-Pachón, L G G Corrêa, S A Rensing, B Kersten, B Mueller-Roeber (2010) PlnTFDB: updated content and new features of the plant transcription factor database. Nucleic Acids Res. 38S:D822-D827.

Ramegowda V, M Senthil-Kumar, K N Nataraja, M K Reddy, K S Mysore, M Udayakumar (2012) Expression of a finger millet transcription factor, EcNAC1, in tobacco confers abiotic stresstolerance. PLoS One 7:1-12.

Rodríguez M, E Canales, O Borrás-Hidalgo (2005) Molecular aspects of abiotic stress in plants. Biotecnol. Apl. 22:1-10.

Saad A S I, X Li, H P Li, T Huang, C S Gao, M W Guo, W Cheng, G Y Zhao, Y C Liao (2013) A rice stress-responsive NAC gene enhances tolerance of transgenic wheat to drought and salt stresses. Plant Sci. 203-204:33-40.

Saibo N J M, T Lourenco, M M Oliveira (2009) Transcription factors and 
regulation of photosynthetic and related metabolism under environmental stresses. Ann. Bot. 103:609-623.

Sakuma Y, K Maruyama, Y Osakabe, F Qin, M Seki, K Shinozaki, K Yamaguchi-Shinozaki (2006) Functional analysis of an Arabidopsis transcription factor, DREB2A, involved in droughtresponsive gene expression. Plant Cell 18:1292-1309.

Shen H, F Chen, R A Dixon (2009) A bioinformatic analysis of NAC genes for plant cell wall development in relation to lignocellulosic. Bioenerg. Res. 2:217-232.

Shen Q, P Zhang, T H Ho (1996) Modular nature of abscisic acid (ABA) response complexes: composite promoter units that are necessary and sufficient for ABA induction of gene expression in barley. Plant Cell 8:1107-1119.

Shinozaki K, K Yamaguchi-Shinozaki (2007) Gene networks involved in drought stress response and tolerance. J. Exp. Bot. 58:221-227.

Song S Y, Y Chen, J Chen, X Y Dai, W H Zhang (2011) Physiological mechanisms underlying OsNAC5-dependent tolerance of rice plants to abiotic stress. Planta 234:331-345.

Tran L S, K Nakashima, Y Sakuma, S D Simpson, Y Fujita, K Maruyama, M Fujita, M Seki, K Shinozaki, K Yamaguchi-Shinozaki (2004) Isolation and functional analysis of Arabidopsis stressinducible NAC transcription factors that bind to a drought responsive cis-element in the early responsive to dehydration stress 1 promoter. Plant Cell 16:2481-2498.

Tran L S, K Nakashima, Y Sakuma, Y Osakabe, F Qin, S D Simpson, K Maruyama, Y Fujita, K Shinozaki, K Yamaguchi-Shinozaki (2007) Co-expression of the stress-inducible zinc finger homeodomain ZFHD1 and NAC transcription factors enhances expression of the ERD1 gene in Arabidopsis. Plant J. 49:46-63.

Tran L S, T N Quach, S K Guttikonda, D L Aldrich, R Kumar, A Neelakandan, B Valliyodan, H T Nguyen (2009) Molecular characterization of stress-inducible GmNAC genes in soybean. Mol. Genet. Genomics 281:647-664.

Verslues P E, M Agarwal, S Katiyar-Agarwal, J Zhu, J K Zhu (2006) Methods and concepts in quantifying resistance to drought, salt and freezing, abiotic stresses that affect plant water status. Plant J. 45:523-539.
Xue G P, H M Way, T Richardson, J Drenth, P A Joyce C L Mclntyre (2011) Overexpression of TaNAC69 leads to enhanced transcript levels of stress up-regulated genes and dehydration tolerance in bread wheat. Mol. Plant 4:697-712.

Yamaguchi-Shinozaki K, K Shinozaki (2006) Transcriptional regulatory networks in cellular responses and tolerance to dehydration and cold stresses. Annu. Rev. Plant Biol. 57:781-803.

Yamaguchi-Shinozaki K, K Shinozaki (1994) A novel cis-acting element in an Arabidopsis gene is involved in responsiveness to drought, low temperature, or high-salt stress. Plant Cell 6:251-264.

Yamasaki K, T Kigawa, M Inoue, S Watanabe, M Tateno, M Seki, K Shinozaki, S Yokoyama (2008) Structures and evolutionary origins of plant-specific transcription factor DNA-binding domains. Plant Physiol. Biochem. 46:394-401.

Yang S D, P J Seo, H K Yoon, C M Park (2011) The Arabidopsis NAC transcription factor VNI2 integrates abscisic acid signals into leaf senescence via the COR/RD genes. Plant Cell 23:2155-2168

Yokotani N, T Ichikawa, Y Kondou, M Matsui, H Hirochika, M Iwabuchi, K Oda (2009) Tolerance to various environmental stresses conferred by the salt-responsive rice gene ONAC063 in transgenic Arabidopsis. Planta 229:1065-1075.

Zhang H, J P Jin, L Tang, Y Zhao, X C Gu, G Gao, J C Luo (2011) Plant TFDB 2.0: update and improvement of the comprehen sive plant transcription factor database. Nucleic Acids Res. 39:D1114-D1117.

Zheng X, B Chen, G Lu, B Han (2009) Overexpression of a NAC transcription factor enhances rice drought and salt tolerance. Biochem. Biophys. Res. Comm. 379:985-989.

Zhong H, Q Q Guo, L Chen, F Ren, Q Q Wang, Y Zheng, X B Li (2012) Two Brassica napus genes encoding NAC transcription factors are involved in response to high-salinity stress. Plant Cell Rep. 31:1991-2003.

Zhou M, D Li, Z Li, Q Hu, C Yang, L Zhu, H Luo (2013) Constitutive expression of a miR319 gene alters plant development and enhances salt and drought tolerance in transgenic creeping bentgrass. Plant Physiol. 161:1375-1391. 